were different from non-minorities.

12. If probability distributions are not familiar, imagine laying out all application files along a straight line on the floor. Place files more to the left when they have a low ex ante probability of admission; and to the right if our statistical procedures indicated that their admission probability was high. Then imagine that folders of applicants who were admitted were sprayed white and the rest red. In Figure 1, the solid line is a smoothed outline of the piles of white folders; the dashed line is a smoothed outline of the piles of red folders.

\section{References}

Achen, Christopher, 1986. The Statistical Analysis of Quasi-experiments. Berkeley: University of California Press.

Dawes, Robyn M. 1982. "The Robust Beauty of Improper Linear Models in Decision Making." In Judgment Under Uncertainty, ed. Daniel Kahenman, Paul Slovic, and Amos Tversky. New York: Cambridge University Press.

King, Gary. 1991. "Stochastic Variation." Political Analysis 2: 185-200.

King, Gary. 1989. Unifying Political Methodology: The Likelihood Theory of Statistical Inference. New York: Cambridge University Press.

King, Gary, Robert O. Keohane, and Sidney Verba. N.d. Designing Social Inquiry: Scientific Inference in Qualitative Research, forthcoming.

\title{
Editing Multiauthor Books in Political Science: Plotting Your Way Through an Academic Minefield*
}

\author{
Clive S. Thomas, University of Alaska Southeast \\ Ronald J. Hrebenar, University of Utah
}

\begin{abstract}
A rough sample taken by wandering around the book exhibits at a recent APSA meeting revealed that about $20 \%$ of all books in political science are compiled by an editor, though the percentage varies considerably among publishers. Editing a multiauthor book is a popular form of publishing within our discipline, and this type of editing has probably crossed most of our minds at some time. If you are seriously thinking about editing a multiauthor book, you should consider three things before making a definite decision.

First, you should be aware of the pros and cons of editing a multiauthor book. Second, you should consider whether your temperament is suited to the task and whether you have the mind for detail and organization that editing a multiauthor volume entails. Third, and most important of all, you need to be aware of the technical factors and procedures that will help to ensure
\end{abstract}

the completion and publication of your book, as well as the many pitfalls that may doom your project to failure.

\section{Pros and Cons of Multiauthor Book Editing}

In terms of enhancing your career, an edited book may not provide what you need. In most political science departments edited books rank just above newspaper articles and non-refereed journal publications and certainly well below textbooks. Some departments don't count edited books as publications. Even if your department looks upon them favorably, don't be fooled into believing that editing a book is a quick and easy way to get a publication. In our experience, editing and dealing with contributors is far more time consuming than writing articles or authoring books. If you are an un-

\section{About the Authors}

Gary King is a Professor of Government, Department of Government, Harvard University. John M. Bruce is Instructor, Department of Government, Georgetown University. Michael Gilligan is Assistant Professor of Politics, Department of Politics, New York University. tenured faculty member, editing can sidetrack you from turning out the refereed journal articles, the book chapters, and the one or two books that will likely assure you of tenure. From a career perspective, it is probably best to wait until you are tenured before you edit a multiauthor book.

There is, however, a positive side to multiauthor editing. As is the case in preparing and teaching a class, you can learn a great deal about a subject from editing a book. With the vantage point of reviewing all the chapters and, if you are a diligent editor, by doing preliminary background work and checking references and material during the editing phase, you will become intimately familiar with the literature in the subject area of your book. This can be of great value in your own writing later.

A well-planned and integrated edited book can make an important 
contribution to your subfield and perhaps the discipline in general. Edited volumes enable information to be amassed that could not be achieved by one or two individual authors without a large grant and an army of research assistants.

Three other advantages can accrue from editing. One is that you may well make some good contacts (and maybe some friends too) who can be of value in the future for collaborating, putting together convention panels, and a host of other things. (But, as we mention below, also be prepared to lose some friends.)

Another is that you can get a tremendous sense of satisfaction and achievement from originating, organizing, and shepherding a project to fruition through what, given the myriad problems of editing, is the academic equivalent of a minefield.

Finally, if you have thoughts or ambitions of becoming a department chair or other administrator, your experience in organizing the book project and in dealing with contributors will give you an indication of your management and interpersonal skills and whether an administrator's life is the one for you. Such experience may also look good on your vita when you are applying for such positions.

\section{Are You Suited To Be an Editor?}

The task of editing a multiauthor volume involves much more than the academic element. In terms of time, it breaks down to about one quarter as an exercise in organizing and managing; another quarter or so involves interpersonal communications as you deal with the contributors; and only about a half involves the academic element.

In many ways the management and interpersonal aspects of the project are the most crucial, especialily at the beginning. Poor skills on the part of the editor in these areas have doomed many a multiauthor volume, with resultant bad feelings on the part of contributors and publisher. The major factor in the success of any multiauthor book is good organization and planning, up-front and throughout the project. With anything from half a dozen to as many as 20 contributors, you need to have a good and up-to-date filing system, a mind for detail, and the fortitude not to be overwhelmed and exasperated by the tedium of administering to the minutiae of the project. Failure to pay attention to what might appear to be a minor detail can cause much pain and suffering later. It may add time to the project or even doom it.

For many editors the most difficult and unforeseen aspect of editing is dealing with certain of the contributors. Like the students in your classes, $85-90 \%$ of your contributors will be nice and cooperative, but it's the $10-15 \%$ problem cases that cause

\section{Edited volumes enable} information to be amassed that could not be achieved by one or two individual authors without a large grant and an army of research assistants.

you difficulties and often much grief. In extreme circumstances they can destroy the project. All projects have their problem people. The more contributors the more likely the problems, and, as E. E. Schattschneider said, the less certain the outcome.

If unfavorable or lukewarm book reviews bother you, then editing is also not for you. It is likely that your book will not be reviewed at all; edited books have less appeal to book review editors than do authored and coauthored volumes.

Most of all, when you take on an edited book, you take on a major responsibility. Several people are trusting you to do what you have said you would do and come through with your key role in coordinating and producing the book project. There will be many times when you want to throw the whole thing in: times when contributors don't deliver, a contributor harangues you because the project is behind schedule, a publisher rejects your manuscript. But you must persevere to overcome the downsides and the disappointments.

If you are a loner who does not have interpersonal and management skills, a thick skin, and a mind for detail (or the desire to develop them), or if you don't want to take on the responsibility to the contributors that is part of the territory of editing a book, then you should not be an editor. But if you have these qualities, and editing appeals to you, take account of the things in the next section before you embark upon a project.

\section{Ten Elements in Successful Editing}

The ten elements set out below are not editing techniques; they are organizational and procedural steps that help to ensure success.

\section{Understanding the Role of the Editor}

We mentioned it above, but it is important to emphasize that editing involves much more than the academic element. An editor is the manager, the ramrod, the wet nurse, and the salesperson as well as the chief academic on the project. There should be no doubt as to who is in charge of the project and who makes the final decisions. This may be difficult when one is a junior scholar dealing with senior, perhaps even big name, contributors, but you have to remain in charge. As soon as you lose control, your project will get away from you.

\section{Planning and Organizing the Project}

Just like good teaching and authoring a good article, chapter, or book, the key to successful book editing is planning and organizing. In fact, these two elements are even more crucial in an edited book because you are trying to integrate the work of many authors with different writing styles and perspectives and probably with varying views about how the book should turn out.

For this reason, you need to give great attention to the focus and themes of the book, and perhaps even run these by a colleague or 
two to get feedback. Before you approach contributors, you need to have a fairly clear idea of the format and contents of the book; you need to have developed some detailed instructions for contributors (see 5 below); you need to have worked out a tentative production schedule for the book; and you need to set up a good filing system for the project.

This is not to say that all these things will be set in concrete. But being and, most importantly, appearing organized will: (1) make your task easier as you deal with masses of paper and inquiries down the road; (2) impress potential contributors who, based on past experience, might otherwise be reluctant to join an edited project-this is especially true if you are relatively unknown in the profession and you want to get some big name people who don't really need another publication; and (3) impress potential publishers. Generally publishers are extremely leery of edited books, for the reasons we related above in describing the pitfalls in editing. Being organized is one way to overcome their aversion and at least get them to look at your prospectus.

\section{Choosing the Right Contributors}

This is a step that is more difficult than it appears on the surface and that is fraught with pitfalls. What one is looking for in a contributor is: (1) a quality contribution in terms of content and style; (2) a willingness to write a piece to fit the focus/themes of the book (in other words, a cooperative person); (3) a person who is willing to make revisions and will not be offended by a first draft critique; and (4) someone who takes the deadlines seriously. From an editor's perspective, points 2,3 , and 4 may prove more important than point $1-$ a quality contribution. This is one of the political compromises of editing, unfortunately.

You don't know people until you've worked with them. And the chances are that the problem contributor will turn out to be someone you least expected to cause you grief. You may have known colleagues for years, been good friends, shared rooms at a convention, gone to their weddings, helped them through their divorces. But working with them, and particularly critiquing their writing, telling them that they have to make major changes, or finding that they don't deliver by the deadline, may reveal a side of them you've never seen before. It can even ruin your relationship. The moral: don't go into editing if you don't want conflict, don't have a thick skin, and don't like making hard decisions.

On the other hand, an editor needs patience and understanding. People do have problems in their lives that genuinely impede their progress on your project, and you have to accommodate them within reason. The problem, however, is distinguishing between the genuine problem and the lame excuse resulting from laziness or overcommitment.

\section{Generally publishers are extremely leery of edited books, for the reasons we related above in describing the pitfalls in editing.}

You can look at the work of potential contributors before approaching them. You can talk to colleagues to find out how easy certain people are to work with and those you should avoid at all costs even though they might be prominent political scientists. What is the use of a contribution by a big name author who won't work to integrate his or her piece with your book's focus, deliver a draft, or make revisions?

This brings us to the question of the mix of prominent political scientists versus unknowns that you should have contributing to your book. Obviously, big name people can help you to get a publisher, and some publishers will be very much concerned with the prominence or lack thereof of your contributors. If you can find one or more big name contributors who are easy to work with, they can add immensely to your project both from an academic and a marketing point of view.

On the other hand, don't dismiss the newly minted Ph.D.s with potential who are hungry for publication and for that reason most willing to work within your focus and deadlines. You can get a fair assessment of their abilities by asking them to send you some of their writing or by picking up their papers at a convention. But once again, be wary of your friends unless you really know them. Remember you are about to embark on a serious academic project-not a social event.

\section{Quality Control}

Just a quick perusal of a few edited books will tell you that quality control is a problem with many multiauthor volumes. This includes the quality of the academic contribution, the writing style, and the integration or cohesion of the book. Quality control is essentially a function of four factors: (1) the contributors you choose; (2) direction from the editor as to what is expected from each author, which is in turn a product of careful planning and communication; (3) your diligence in editing first drafts and your fortitude to make some hard decisions at this stage; and (4) your skills as the project coordinator. We have already addressed point 1 and some of point 2 . The following sections provide more insights on this second point and treat the first draft and the coordinator factors.

\section{Developing a Detailed Set of Guidelines for Contributors}

It is absolutely essential that you develop a set of written instructions or guidelines for the contributors to the book. Furthermore, you should leave nothing to chance and be as inclusive in these guidelines as possible. This may seem overkill to the neophyte editor and somewhat of an insult to the senior, perhaps big name, contributors that you are hoping to secure. But think of it from the perspective of maximizing work efficiency for all concerned. Then it becomes clear why a set of comprehensive guidelines is a must.

First, written, comprehensive guidelines make it easier for each contributor to work exactly to your specifications both in terms of content and format. This saves you time on the phone and at your computer answering questions and clarifying vague directions. And most con- 
tributors will be very appreciative of specific direction-it saves them from wasting time on content and format that will have to be changed later, changes that may well make them angry with you for not having been specific in the first place. Second, guidelines reduce the risk of a lack of cohesion in the manuscript. Third, guidelines help to ensure a good, fairly complete first draft. This is important because most contributors put their major effort into a first draft. A good, fairly complete first draft is also a valuable asset when you start to approach publishers.

Comprehensive guidelines are also useful for two other reasons. They convey to potential contributors that you are very serious about your project. The faint of heart and the contributor who is looking for a quick and easy publication may think twice before signing on. In fact, you should think twice about anyone who complains about your guidelines before signing on. This is often the first sign of a problem contributor. Comprehensive guidelines also convey to publishers that your project is well thought out.

At a very minimum your guidelines for contributors should contain the following sections: (1) the focus and themes of the book; (2) common elements required in each chapter to aid in integration and cohesion; (3) format, length limitation, note/ reference/bibliography style; (4) project timelines for the submission and return of drafts; (5) times and places that the contributors can contact you. Depending on the specific project, other sections setting out common definitions or detailing methodology may also be appropriate. Another section that is often of great value is one detailing what contributors should not include in their chapter such as definitions, a review of the literature, and so on, because these will be covered in the editor's introduction.

\section{The Psychology of the Contributor}

As an editor it is important to be aware of how contributors view a project and to be cognizant of the psychological phases that they go through as the project progresses. If you have been a contributor, this will be fairly easy to gauge; but if you have not, or if you have never given the matter much thought, here are some pointers.

First, while as editor this project is one of the most important things in the world to you, to most contributors it is probably just another publication. After all, yours is the only name that will appear on the cover of the book. Many of your contributors probably won't even read their own chapters once the book is published, let alone the other chapters. This means that you must be realistic about the level of commitment and the goals of your contributors. Their primary goal is to get their chapters written and published

\section{Just a quick perusal of a few edited books will tell you that quality control is a problem with many multiauthor volumes.}

as quickly and as efficiently as possible, with the minimum of changes beyond the first draft.

In terms of the psychological phases that contributors go through, they develop something like this. Stage 1 is euphoria: you've given them an ego boost, recognizing their talents by asking them to contribute to a project. Stage 2 is slight panic as they work to get the first drafts in on time or scheme to think up excuses for why they will be late. Stage 3 is a combination of exhaustion and relief as they mail off the first draft to you. This stage is probably the contributors' peak of interest in the project. After this their interest will start to wane, and they will be in Stage 4-the "this project is getting tedious" phase. This is why it is essential to get the best first draft that you can and to request only minor changes after that (though things do not always work out this way).

If things do not move along rapidly after this-if you have a problem getting a publisher, if some contributors hold up the project by not doing revisions and so on-many of your contributors may progress to Stage 5-exasperation. Further problems may lead them into Stage 6alienation-when they simply give up. If your contributors get to Stages 5 and 6 , you have serious problems and your project may be doomed. Obviously, one of your major goals as project manager is to prevent your contributors from reaching these phases.

\section{A Crucial Juncture: The First Draft Stage of the Project}

So far, we have mentioned several reasons why the first draft stage of the project is so crucial. There are two additional important reasons.

One is the need to deal with chapters that are poor or do not reflect your guidelines for chapter content. The poor chapter is one that is superficially researched, badly written, and generally the sort of thing you wouldn't accept from a sophomore. A variation on this is that often a contributor will try to palm off on you a chapter that is in the area but nowhere near your specifications. This is probably an article or chapter that they could not place somewhere else; or a dusted-off conference paper that they are sending because they misjudged how much work was involved in their chapter and they wanted to get something to you before the deadline. Yet another variation on this is that often people do not read your guidelines and just turn in the chapter that they wanted to write. Perhaps the most common complaint and cause of exasperation among editors is this seeming lack of regard by contributors for what the editor is trying to do. It has been a very common experience in all of our editing projects.

This is where some tough decisions have to be made by the editor-decisions that can make or break your project. You need to tackle each of these three situations head-on, unpleasant as the prospect may be.

As to poor chapters, one of the major lessons that we have learned as editors, a lesson that many other editors will corroborate, is that if someone does a really bad first draft, given all the direction and support you have provided, the chances are 
that they will not do a good second draft. You should probably find another contributor for this chapter or eliminate it from the book if possible.

The other two cases-the palmedoff chapter and the one ignoring your guidelines-may be salvageable; but you need some concrete guarantees. If in doubt, find another contributor. This sounds drastic. It will certainly add time to the project and probably upset, maybe outrage, these contributors. But the alternatives are even less pleasant: adding much more time to the project as these contributors dally and then perhaps don't deliver; compounding your problems in finding a publisher; and in the end, if your project has to be abandoned, running the risk of alienating all your contributors.

The other important aspect of the first draft stage is to do a thorough job of editing. This seems obvious; but many editors don't take the trouble to do it because it is hard work, tedious, and runs the risk of bruising some egos. But this is your major and maybe your last chance, until you can secure a publisher, to get changes made that will improve the quality, cohesiveness, and format of the manuscript.

\section{Dealing with Contributors and the Problem Contributor}

As an editor you must keep your contributors informed about what's going on: status of the project, changes in timelines, and so on. This includes informing them of the bad news as well as the good. The worst thing that can happen to you is for one of your contributors to find out some bad news-rejection of a manuscript by a publisher, a delay in publication-from someone other than you. It leads to bad feelings, and if it happens frequently it can even precipitate Stage 6 of contributor psychology-alienation. Set aside a time slot or two each week when your contributors can call you. Communicate with them regularly; even if there is no real progress to report, you should tell them that. And be prepared to write lots of letters of recommendation for them for promotion and tenure and letters verifying their participation in the project. This is part of the responsibilities that come with the territory of being an editor.

There are several ways to deal with problem contributors. One, as we have suggested above, is to get rid of them when you find that they don't deliver. This is not easy; but it will likely turn out to be the best thing you did for the project. If you can't stomach this, then you will probably end up rewriting the chapter yourself; this may be the only way to salvage it. Then there are contributors who do satisfactory or good work but have fragile egos and get upset at your suggested changes. These you can deal with by smoothing their

\section{Perhaps the most common complaint and cause of exasperation among editors is this seeming lack of regard by contributors for what the editor is trying to do.}

egos and giving them lots of praise for their work. Then there are those who constantly call you-sometimes to harangue you-because the book wasn't published yesterday. Often these are people who have never edited or published a book themselves, and so are not familiar with the intricacies and pitfalls of the process. The best way to handle them is to keep them well informed of the progress-or lack thereof-of the project and to explain to them and be up-front about any problems you are encountering.

\section{Approaching a Publisher and Securing a Contract}

Unless you are a star in the profession, have a project that is studded with stars, or an edited book that has a large potential market, the chances are that you won't get a contract until you can send the entire manuscript to a publisher. This means that in organizing an edited book you ask the contributors to embark upon a project with a far from certain outcome; and as editor, from the very beginning of the project you incur a major obligation and put youself under great pressure to come through with a contract.

There are three key factors in getting a publisher interested in your edited book project and in ultimately securing a contract. First, you have got to approach the right publishers. Not all publishers will be interested in your particular subject and some - especially some of the larger commercial houses-will not be interested in edited books. You can find out which publishers might be interested by perusing the booths at a convention, examining the literature, talking to colleagues, or calling up an editor. Second, you have to overcome most publishers' natural aversion to edited books. This you can do by showing that you really have a well-thoughtout and organized project. This can be evidenced by a well-written prospectus, a comprehensive set of contributor guidelines, other supporting materials such as the vitae of contributors, research on the potential market, and a good first draft of the manuscript.

Once you've gotten the attention of a publisher who is seriously considering your project the third key factor comes into play: you and your contributors must be willing to make most of the changes that the publisher wants based on reviews of the manuscript. Because publishers are rarely experts in your field, they rely heavily on their reviewers, who frequently suggest many revisions. Such changes can cause trauma for you and your contributors. However, securing a contract will probably hinge on your willingness to go along with most of these changes whether you like them or not. Taking the publisher and the reviewers head-on and arguing against or refusing to make the major changes will probably result in rejection of your manuscript. Despite the problems and tedium of dealing with these changes, you can find some comfort in the fact that once you are close to a contract it is easier to reinvigorate your contributors to make the needed revisions. 
10. Moving the Project Through the Publication and Marketing Process

It is obvious that you need to build up a good relationship with your assigned editor and the other production staff at your publisher to ensure that your manuscript gets produced in the best way possible. There is much more to these final stages of the process, however. In many ways this is the phase when attention to fine detail is most crucial as you and your contributors review the edited copy and the page proofs of the manuscript. By now, almost everyone is tired of the project, has moved on to other things, and, consequently, may be much less diligent than is necessary to avoid glaring errors that will turn up in the printed book. For this reason it may be wise to find someone-a graduate student, a colleague, or a professional proofreader - to help you in proofing the manuscript.

Finally, a few words about marketing your manuscript. If marketing is important to you, you should be aware that some publishers are much better at this process than others; and that some are less concerned about it even though they would never admit it. The big commercial publishers are obviously in it for the money and do a first-rate job of marketing. But most of these do few edited books. Some of the smaller commercial houses rely most on library sales and will mount only a token general marketing effort. University presses are more likely to be interested in an edited book; but their marketing efforts vary from very good to not so good to pathetic. The upshot of all this is that you may want to get actively involved in the marketing effort for your book: work closely with the marketing staff at the press; get the word out to journals and other publications; maybe send a letter to interested colleagues; or even develop your own dedicated mailing list. For example, we developed and gave to each of our publishers a mailing list of 5,600 names of those who might be interested in purchasing books from our five-book series on interest groups in the 50 states.

These, then, are what we see as the ten key factors in successfully organizing and completing an edited book project, the pros and cons of editing, and some criteria that you can use to determine whether or not you should take on an edited book. To be sure, many edited books have been published that followed a far

Unless you are a star in the profession, have a project that is studded with stars, or an edited book that has a large potential market, the chances are that you won't get a contract until you can send the entire manuscript to a publisher.

less strict organizational scheme and had a less controlling editor than we are recommending here.

Furthermore, experienced editors will disagree on the importance of all these points and recommendations. Nevertheless, the vast majority of seasoned editors and many of those whose projects didn't make it will tell you that the factors set out here are certainly key elements to success in editing a multiauthor book. Our experience has taught us that to ignore any of these factors is to add extra, potentially very destructive, mines to an already well-peppered academic minefield.

\section{Note}

*The authors thank Susan A. Burke for her comments on the first two drafts of this manuscript.

The central themes of this article are based on the extensive experience of the authors in editing multiauthor books over a ten-year period. However, attendance at the 1992 APSA roundtable discussion on Managing a Multi-Author Research Project in Comparative Politics was useful in refining several of the points. We wish to acknowledge the contributions of that roundtable's members: Chair, Kent Weaver, Brookings Institution; Joel D. Aberbach, UCLA; Keith Banting, Queen's University; Nancy Davidson, Brookings Institution; T. J. Pempel, University of Colorado; and Sidney Verba, Harvard.

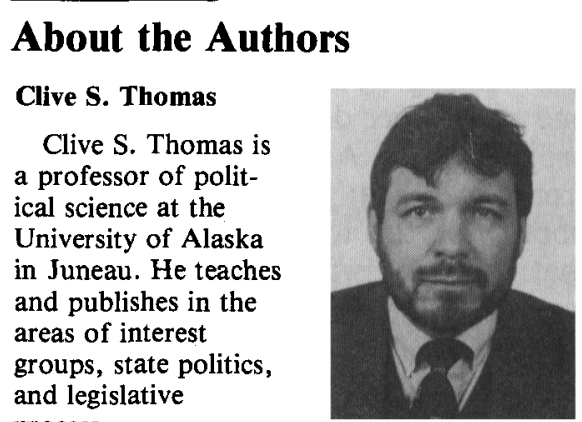
process.

\section{Ronald J. Hrebenar \\ Ronald J. Hrebenar is a professor of political science at the University of Utah. His teaching and pub- lications focus on interest groups, polit- ical parties, and Japanese politics.}

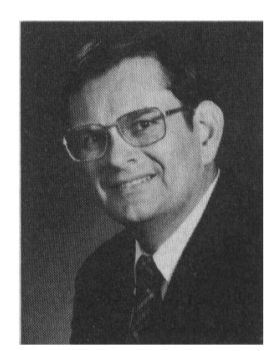

